Aim of the study: Systemic chemotherapy for patients with pancreatic cancer has limited impact on overall survival (OS). Patients eligible for chemotherapy should be selected carefully. The aim of the study was to search for prognostic factors for survival in patients with gemcitabine (Gem)-refractory or with gemcitabine and cisplatin (GemCis)-refractory advanced pancreatic cancer.

Material and methods: We retrospectively evaluated patients with Gem- or GemCis-refractory advanced pancreatic cancer. Sixteen potential prognostic variables were chosen for analysis in this study. Univariate and multivariate analyses were conducted to identify prognostic factors associated with survival. Univariate and multivariate statistical methods were used to determine prognostic factors.

Results: Multivariate analysis included the four prognostic significance factors in univariate analysis. Multivariate analysis showed that liver metastasis and second-line chemotherapy were considered independent prognostic factors for survival.

Conclusions: Liver metastasis and second-line chemotherapy were identified as important prognostic factors in advanced pancreatic cancer patients refractory to treatment with Gem or GemCis. This prognostic factors may also facilitate pretreatment prediction of survival and can be used for selecting patients for treatment.

Key words: pancreatic cancer, gemcitabine-refractory patients, prognostic factors.

Contemp Oncol (Pozn) 2015; 19 (2): 125-129 DOI: $10.5114 /$ wo.2014.43933

\section{Prognostic factors for gemcitabine- refractory patients with advanced pancreatic cancer: a retrospective analysis of a multicentre study (Anatolian Society of Medical Oncology)}

Ali İnal ${ }^{1}$, F. Tuba Kos², Efnan Algın², Ramazan Yıldız', Veli Berk ${ }^{5}$, ilkay T. Unek Dilsen Colak ${ }^{7}$, Faysal Dane ${ }^{8}$, Caglayan Geredeli ${ }^{9}$, Abdurrahman Isıkdogan ${ }^{10}$

\author{
${ }^{1}$ Department of Medical Oncology, School of Medicine, Dicle University, Diyarbakır, Turkey \\ 2Department of Medical Oncology, Ankara Numune Education and Research Hospital, \\ Ankara, Turkey \\ ${ }^{3}$ Department of Medical Oncology, Gazi University, Ankara, Turkey \\ ${ }^{4}$ Dr. Lütfi Kirdar Kartal Education and Research Hospital, İstanbul, Turkey \\ ${ }^{5}$ Department of Medical Oncology, Erciyes University, Kayseri, Turkey \\ ${ }^{6}$ Department of Medical Oncology, Dokuz Eylül University, İzmir, Turkey \\ YYıldırım Beyazıt Education and Research Hospital, Ankara, Turkey \\ ${ }^{8}$ Marmara University School of Medicine, Division of Medical Oncology, Istanbul, Turkey \\ ${ }^{9}$ Secuk University, Meram Medical Faculty, Konya, Turkey \\ ${ }^{10}$ Department of Medical Oncology, Dicle University, Diyarbakır, Turkey
}

\section{Introduction}

Pancreatic cancer is the fourth most common cause of cancer-related deaths in the United States [1]. Surgery is the only potentially curative treatment, while only $10-20 \%$ of these patients present with surgically resectable disease. Without effective treatment, the median survival for locally advanced disease is 8 to 12 months and only 3 to 6 months for metastatic disease. The overall 5 -year survival rate among pancreatic cancer patients is still less than $5 \%[2-4]$

Systemic chemotherapy with single-agent gemcitabine (Gem) is currently recommended as a standard first-line chemotherapy in pancreatic cancer patients [5-7]. Systemic chemotherapy for patients with advanced pancreatic cancer has limited impact on overall survival (OS), not merely due to low response rates, but also because of severe adverse effects [8-10]. Patients eligible for chemotherapy should be selected carefully. Very different prognostic factors in several trials have been identified for survival in patients with advanced pancreatic cancer [11-15].

Systemic chemotherapy with gemcitabine (Gem) or gemcitabine plus cisplatin (GemCis) is still considered the first choice, which presents a modest survival advantage. However, patients with advanced pancreatic cancer eventually experience disease progression and require second-line therapy. In spite of the clinical benefit of second-line treatments, the toxicity profile has long been observed with clinical interest. While there are reliable predictors to identify patients receiving first-line chemotherapy [11-15], very little knowledge is available about the prognostic factors in patients with Gem- or GemCis-refractory pancreatic cancer $[16,17]$. Furthermore, it is necessary to properly treat patients with either additional chemotherapy or best supportive care. Nakachi et al. [16] suggest that performance status, peritoneal dissemination and C-reactive protein (CRP) levels were identified as important prognostic factors in patients with Gem-refractory pancreatic cancer. 
We performed a multicentre retrospective analysis of prognostic factors in patients with Gem- or GemCis-refractory advanced pancreatic cancer.

\section{Material and methods}

\section{Patient population}

We retrospectively evaluated for pancreatic cancer in patients with Gem or GemCis-refractory advanced pancreatic cancer from February 2003 to October 2011. Gem- or GemCis-refractory pancreatic cancer was defined as pancreatic cancer with progression after chemotherapy with Gem or GemCis.

We retrospectively selected patients who met the following criteria: 1) $\geq 18$ years old; 2) confirmed pathologically pancreatic adenocarcinoma; 3) chemotherapy and or radiotherapy naive; 4) progression of pancreatic cancer after chemotherapy; and 5) disease measured with the use of RECIST version 1.0 (Response Evaluation Criteria in Solid Tumours).

We retrospectively were selected carefully based on the following criteria: 1) they were 18 years or older in age; 2) they had histologic or cytologic diagnosis advanced pancreatic adenocarcinoma; 3) no previous chemotherapy or radiotherapy; 4) they were progresses after chemotherapy with Gem or GemCis; 5) they had to have measurable disease.

\section{Treatment and assessment}

Gem was administrated at $1000 \mathrm{mg} / \mathrm{m}^{2}$ IV over $30 \mathrm{~min}$ utes on day 1 and 8 every 21-day schedule. Cisplatin was added to the gemcitabine schedule at $70 \mathrm{mg} / \mathrm{m}^{2}$ on day 1 for every 21-day cycle. Tumour response was documented by computed tomography imaging according to the Response Evaluation Criteria in Solid Tumours (RECIST 1.0) at baseline and then every three cycles. Disease progression was defined as verification of progressive disease (PD) according to RECIST criteria or clinical deterioration of the patient's general status.

\section{Analysed variables as potential clinically relevant factors}

Sixteen potential prognostic variables were chosen on the basis of previously published clinical trials. The vari-

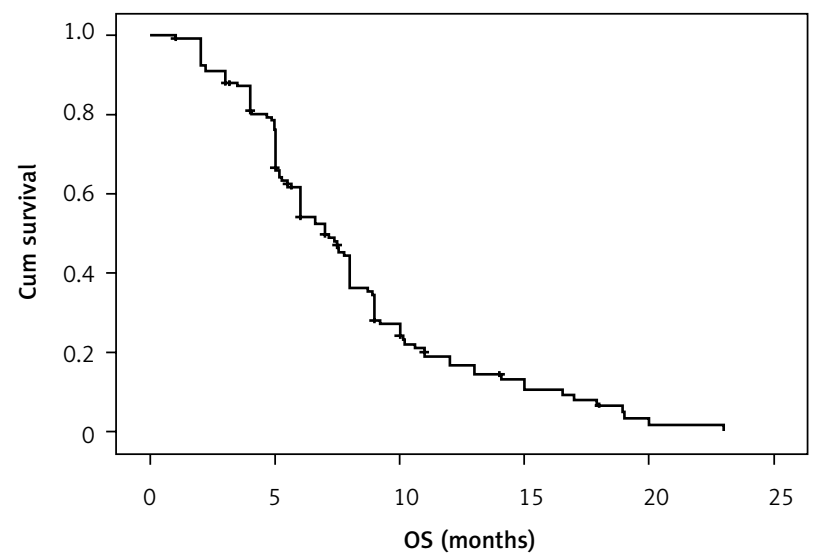

Fig. 1. Overall survivall in all patients. OS: Median 7 months (1-23) ables were divided into two lines in each category: age (<65 or $\geq 65$ years), gender (male or female), performance status (0-1, 2-3), location of primary tumour (head or body-tail), grade (good, poor or moderate), stage (locally advanced or metastatic disease), first-line chemotherapy (Gem or GemCis), second-line chemotherapy (present or absent), the presence of diabetes mellitus at diagnosis, the presence of cholestasis at diagnosis, weight loss $\geq 10 \%$, liver metastasis, lung metastasis, peritoneal dissemination, serum carcinoembryonic antigen (CEA) level $(<8.8$ or $\geq 8.8 \mathrm{ng} / \mathrm{ml})$ and serum carbohydrate antigen 19-9 (CA19-9) level (< 1000 or $\geq 1000 \mathrm{U} / \mathrm{ml})$ at the time of first-line chemotherapy administration.

\section{Statistical analysis}

All of the analyses were performed using the SPSS statistical software program package (SPSS version 11.0 for windows). The differences of the clinical characteristics between the two groups were analysed by $\chi^{2}$ test and student $t$ test. Overall survival was calculated with the logrank test. The Kaplan-Meier method was used for survival curves. Differences were assumed to be significant when the $p$ value was less than 0.05 .

\section{Results}

\section{Patient characteristics}

Between February 2003 and October 2011, 145 patients with Gem- or GemCis-refractory advanced pancreatic cancer were enrolled in this study. Seventy-six patients were treated with single-agent Gem. Sixty-nine patients were treated with GemCis. The median age of patients was 60.0 years (range 32-81) with 103 males and 42 females. Forty-one patients (33.1\%) received second-line chemotherapy. The median OS was 7.0 months (Fig. 1). The patients' baseline characteristics are listed in Table 1.

\section{Prognostic factor analysis}

The results of univariate analysis are summarised in Table 2. Among the sixteen clinical variables of univariate analysis, two variables were identified to have prognostic significance: liver metastasis ( $p=0.004)$ and second-line chemotherapy ( $p=0.001)$.

Multivariate analysis included the four prognostic significance factors in univariate analysis. The results of multivariate analysis are shown in Table 3. Multivariate analysis by Cox proportional hazard model showed that liver metastasis ( $p=0.001)$ and second-line chemotherapy ( $p=0.001)$ were considered independent prognostic factors for survival (Figs. 2, 3).

\section{Discussion}

Systemic chemotherapy for patients with pancreatic cancer has limited impact on OS due not only to low response rates, but also because of severe side effects. Without effective treatment, the median survival for locally advanced disease is 8 to 12 months and only 3 to 6 months for metastatic disease. The overall 5 -year survival rate among pancreatic cancer patients is still less than $5 \%$ [2-4]. 
Table 1. General characteristics of the patients

$\begin{array}{lc}\text { Characteristic } & \text { No. of patients (\%) } \\ \text { Sex } & \\ \text { male } & 103(71.0) \\ \text { female } & 42(29.0) \\ \text { Age, median (range) } & 60.0(32-81) \\ \text { Age } & \\ <65 & 92(63.4) \\ \geq 65 & 53(36.6) \\ \text { Performance status } & \\ \text { 0-1 } & 7(4.8) \\ \text { 2-3 } & 43(29.7) \\ \text { unknown } & 95(65.5) \\ \text { Grade } & \\ \text { good } & 7(4.8) \\ \text { poor or moderate } & 43(29.7) \\ \text { no data } & 95(65.5) \\ \text { Stage } & \\ \text { locally advanced } & 39(26.9) \\ \text { metastatic } & 106(73.1) \\ \text { Location of primary tumour } & \\ \text { head } & 92(63.4) \\ \text { body-tail } & 45(31.0) \\ \text { unknown } & 8(5.5) \\ \text { First-line chemotherapy } & \\ \text { Gem } & 76(52.4) \\ \text { GemCis } & 69(47.6) \\ \text { Diabetes mellitus } & 49(33.8) \\ \text { Cholestasis } & 32(22.1) \\ \text { Weight loss } & 69(48.6) \\ \text { Metastatic sites } & \\ \text { liver } & 87(63.0) \\ \text { lung } & 13(9.6) \\ \text { peritoneum } & 6(4.5) \\ \text { Second-line chemotherapy } & 41(33.1) \\ \text { OS, median (range) } & 7(1-23) \\ \text { Laboratory parameters (median) } \\ \text { CEA (ng/ml) } \\ \text { CA19-9 (ng/ml) } \\ \end{array}$

Patients eligible for chemotherapy should be selected carefully. This retrospective multicentre study analysed prognostic factors for survival in pancreatic cancer patients with Gem- or GemCis-refractory advanced pancreatic cancer.

On univariate analysis, four of sixteen potential factors were identified as significant prognostic factors for survival. However, three independent significant prognostic factors were found on multivariate analysis: location of primary tumour, liver metastasis and second-line chemotherapy.

To identify the prognostic factors of advanced pancreatic cancer before first-line chemotherapy, numerous clinical studies have been done [11-15]. However, very few studies were carried out for the prognostic factors in patients with Gem-refractory advanced pancreatic cancer [16, 17]. In these clinical studies, the location of the primary tumour was not evaluated. In our retrospective study, we found that the location of the primary tumour was not associated with regard to its prognostic importance for survival.
Table 2. Univariate analysis of survival time by categorical variable

\begin{tabular}{|c|c|c|c|}
\hline Variable & $\begin{array}{c}\text { Median } \\
\text { survival } \\
\text { (months), } \\
95 \% \mathrm{Cl}\end{array}$ & $\begin{array}{l}\text { Log- } \\
\text { rank } \\
\text { test } \\
\text { value }\end{array}$ & $p$ \\
\hline $\begin{array}{l}\text { Sex } \\
\text { male } \\
\text { female }\end{array}$ & $\begin{array}{l}6.6(5.1-8.0) \\
8.0(6.2-9.7)\end{array}$ & 1.8 & 0.17 \\
\hline $\begin{array}{l}\text { Age (years) } \\
<65 \\
\geq 65\end{array}$ & $\begin{array}{l}7.1(6.2-8.1) \\
6.0(4.5-7.4)\end{array}$ & 0.01 & 0.97 \\
\hline $\begin{array}{l}\text { Location of primary tumor } \\
\text { head } \\
\text { body-tail }\end{array}$ & $\begin{array}{l}6.0(4.8-7.1) \\
7.7(5.5-9.9)\end{array}$ & 3.2 & 0.06 \\
\hline $\begin{array}{l}\text { Grade } \\
\text { well } \\
\text { poor or moderate }\end{array}$ & $\begin{array}{l}4.0(1-11.2) \\
6.0(4.5-7.4)\end{array}$ & 0.1 & 0.68 \\
\hline $\begin{array}{l}\text { Stage } \\
\text { locally advanced } \\
\text { metastatic disease }\end{array}$ & $\begin{array}{l}8.7(7.4-9.9) \\
6.0(4.4-7.5)\end{array}$ & 3.4 & 0.06 \\
\hline $\begin{array}{l}\text { Performance status } \\
0-1 \\
2-3\end{array}$ & $\begin{array}{c}6.0(4.8-7.1) \\
7.4(4.9-10.0)\end{array}$ & 0.1 & 0.68 \\
\hline $\begin{array}{l}\text { Cholestasis } \\
\text { present } \\
\text { absent }\end{array}$ & $\begin{array}{c}7.5(4.8-10.1) \\
6.6(5.3-7.8)\end{array}$ & 0.08 & 0.77 \\
\hline $\begin{array}{l}\text { Weight loss } \\
\text { present } \\
\text { absent }\end{array}$ & $\begin{array}{l}6.0(4.3-7.6) \\
7.5(6.2-8.8)\end{array}$ & 0.1 & 0.71 \\
\hline $\begin{array}{l}\text { Diabetes mellitus } \\
\text { present } \\
\text { absent }\end{array}$ & $\begin{array}{l}6.0(5.3-6.6) \\
7.7(7.2-8.3)\end{array}$ & 1.2 & 0.26 \\
\hline $\begin{array}{l}\text { Liver metastasis } \\
\text { present } \\
\text { absent }\end{array}$ & $\begin{array}{c}6.0(5.3-6.6) \\
9.0(7.9-10.0)\end{array}$ & 8.4 & 0.004 \\
\hline $\begin{array}{l}\text { Peritoneal dissemination } \\
\text { present } \\
\text { absent }\end{array}$ & $\begin{array}{l}4.0(0.3-7.6) \\
7.3(6.4-8.3)\end{array}$ & 2.8 & 0.09 \\
\hline $\begin{array}{l}\text { Lung metastasis } \\
\text { present } \\
\text { absent }\end{array}$ & $\begin{array}{l}5.0(3.3-6.6) \\
7.1(6.2-8.1)\end{array}$ & 0.3 & 0.57 \\
\hline $\begin{array}{l}\text { First-line chemotherapy } \\
\text { Gem } \\
\text { GemCis }\end{array}$ & $\begin{array}{l}6.0(4.8-7.1) \\
7.5(6.5-8.5)\end{array}$ & 1.6 & 0.2 \\
\hline $\begin{array}{l}\text { Second-line chemotherapy } \\
\text { present } \\
\text { absent }\end{array}$ & $\begin{array}{c}10.0(7.7-12.2) \\
5.6(5.1-6.0)\end{array}$ & 18.4 & 0.001 \\
\hline $\begin{array}{l}\text { CEA }(\mathrm{ng} / \mathrm{ml}) \\
\quad<8.8 \\
\quad \geq 8.8\end{array}$ & $\begin{array}{l}7.3(3.1-11.6) \\
7.5(5.7-9.3)\end{array}$ & 0.3 & 0.57 \\
\hline $\begin{array}{l}\text { CA19-9 } \\
\quad<1000 \\
\geq 1000\end{array}$ & $\begin{array}{c}7.5(4.9-10.0) \\
6.0(4.8-7.1)\end{array}$ & 0.7 & 0.39 \\
\hline
\end{tabular}

Liver metastasis was not found to be an independent prognostic factor for OS in patients with Gem-refractory advanced pancreatic cancer $[16,17]$, whereas in our retrospective study liver metastasis was associated with overall survival. The liver metastasis was associated with shorter survival due to several factors, among them de- 
Table 3. Multivariate analysis of prognostic factors

\begin{tabular}{lccc|} 
Parameter & OR & $95 \% \mathrm{Cl}$ & $P$ value \\
Liver metastasis & 2.18 & $1.38-3.45$ & 0.001 \\
Second-line chemotherapy & 0.35 & $0.21-0.60$ & 0.001
\end{tabular}

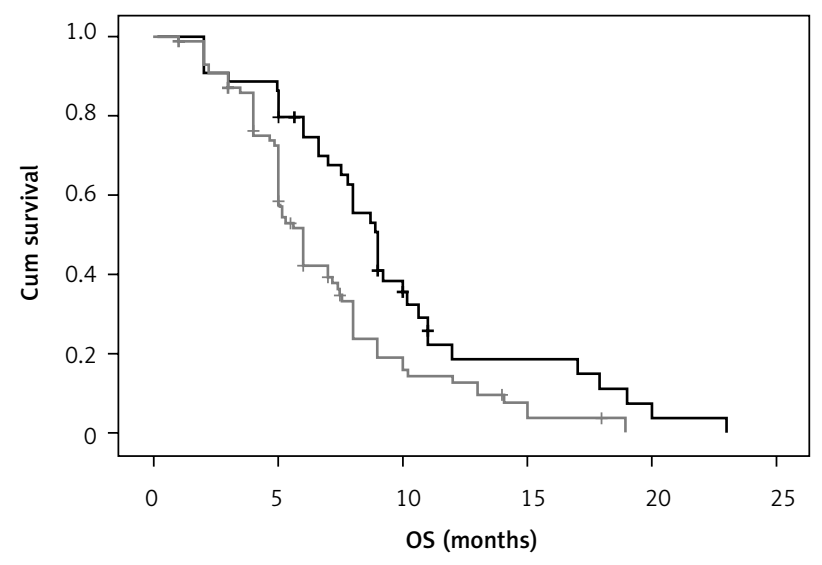

liver metastasis

$\neg$ absent $\neg$ present + absent-censored + present-censored

Fig. 2. Survival of patients according to liver metastasis $(p=0.001)$

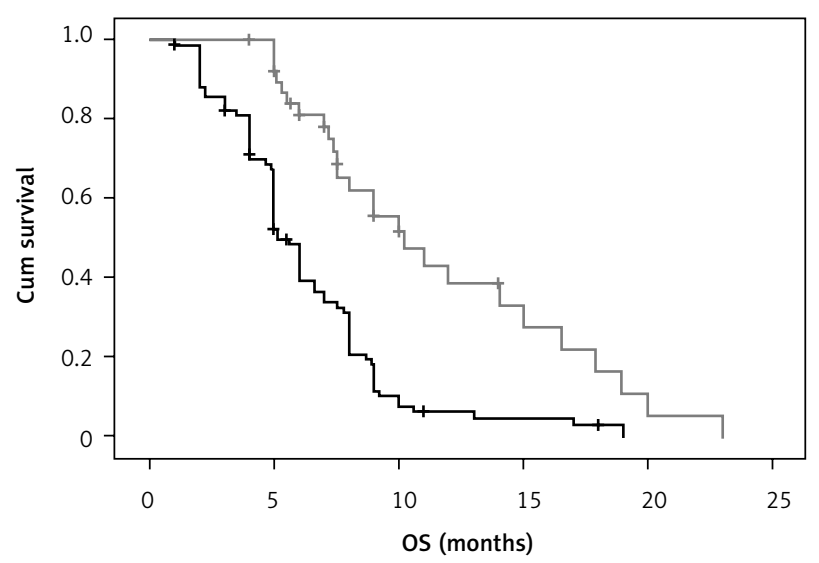

$\neg$ yok $\rightarrow$ pecond-line chemotherapy

Fig. 3. Survival of patients according to second-line chemotherapy $(p=0.001)$

layed start of chemotherapy because of impaired liver function.

According to Maréchal et al. [17], second-line chemotherapy was found in univariate analysis, while multivariate analysis by Cox proportional hazard model did not show as an independent prognostic factor for survival in patients with Gem-refractory advanced pancreatic cancer. In this study, second-line chemotherapy was identified as an independent prognostic factor.

In conclusion, liver metastasis and second-line chemotherapy were identified as important prognostic factors in advanced pancreatic cancer patients refractory to treatment with Gem or GemCis. These prognostic factors may also facilitate pretreatment prediction of survival and could be used for selecting patients for treatment. Therefore, prospective and larger clinical trials are needed.

The authors declare no conflict of interests.

\section{References}

1. Jemal A, Siegel R, Ward E, Hao Y, Xu J, Murray T, Thun MJ. Cancer statistics, 2008. CA Cancer J Clin 2008; 58: 71-96.

2. Li D, Xie K, Wolff R, Abbruzzese JL. Pancreatic cancer. Lancet 2004; 363: 1049-57.

3. Evans DB, Abbruzzese JL, Willett CG. Cancer of the pancreas. In: DeVita VT, Hellman S, Rosenberg SA (eds.). Cancer - principles and practice of oncology. 6th ed. Lippincott and Wilkins; Philadelphia 2001; 1126-61.

4. Cooperman AM. Pancreatic cancer: the bigger picture. Surg Clin North Am 2001; 81: 557-74.

5. National Comprehensive Cancer Network. Clinical Practice Guidelines in Oncology: Pancreatic adenocarcinoma version 1.2009. Fort Washington, PA, National Comprehensive Cancer Network 2009.

6. Burris HA 3rd, Moore MJ, Andersen J, et al. Improvements in survival and clinical benefit with gemcitabine as first-line chemotherapy for patient with advanced pancreas cancer: a randomised trial. J Clin Oncol 1997; 15: 2403-13.

7. Heinemann V, Labianca R, Hinke A, Louvet C. Increased survival using platinum analog combined with gemcitabine as compared to single-agent gemcitabine in advanced pancreatic cancer: Pooled analysis of two randomized trials, the GERCOR/GISCAD intergroup study and a German multicenter study. Ann Oncol 2007; 18: 1652-9.

8. Heinemann V, Quietzsch D, Gieseler F, et al. Randomized phase III trial of gemcitabine plus cisplatin compared with gemcit abine alone in advanced pancreatic cancer. J Clin Oncol 2006; 24: 3946-52.

9. Viret F, Ychou M, Lepille D. Gemcitabine in combination with cisplatin versus gemcitabine alone in the treatment of locally advanced or metastatic pancreatic cancer: final results of a multicenter randomized phase II study. Proc Am Soc Clin Oncol 2004; 22 (abstr. 4118)

10. Colucci G, Giuliani F, Gebbia V, et al. Gemcitabine alone or with cisplatin for the treatment of patients with locally advanced and/ or metastatic pancreatic carcinoma: a prospective, randomized phase III study of the Gruppo Oncologico dell'Italia Meridionale. Cancer 2002; 94: 902-10.

11. Papadoniou N, Kosmas C, Gennatas K, et al. Prognostic factors in patients with locally advanced (unresectable) or metastatic pancreatic adenocarcinoma: a retrospective analysis. Anticancer Res 2008; 28: 543-9.

12. Shimoda M, Katoh M, Kita J, Sawada T, Kubota K. The Glasgow Prognostic Score is a good predictor of treatment outcome in patients with unresectable pancreatic cancer. Chemotherapy 2010; 56: 501-6.

13. Engelken FJ, Bettschart V, Rahman MQ, Parks RW, Garden OJ. Prog nostic factors in the palliation of pancreatic cancer. Eur J Surg Oncol 2003; 29: 368-73.

14. Hammad N, Heilbrun LK, Philip PA, Shields AF, Zalupski MM, Venkatramanamoorthy R, El-Rayes BF. CA19-9 as a predictor of tumor response and survival in patients with advanced pancreatic cancer treated with gemcitabine based chemotherapy. Asia Pac J Clin Oncol 2010; 6: 98-105.

15. Ueno H, Okada S, Okusaka T, Ikeda M. Prognostic factors in patients with metastatic pancreatic adenocarcinoma receiving systemic chemotherapy. Oncology 2000; 59: 296-301.

16. Nakachi K, Furuse J, Ishii H, Suzuki E, Yoshino M. Prognostic factors in patients with gemcitabine-refractory pancreatic cancer. Jpn J Clin Oncol 2007; 37: 114-20.

17. Maréchal R, Demols A, Gay F, De Maertelaere V, Arvanitaki M, Hendlisz A, Van Laethem JL. Prognostic factors and prognostic 
index for chemonaïve and gemcitabine-refractory patients with advanced pancreatic cancer. Oncology 2007; 73: 41-51.

\section{Address for correspondence}

\section{Ali Inal MD}

Department of Medical Oncology

Dicle University, School of Medicine

Diyarbakır, Turkey

tel. 904122488001

fax 904122488440

e-mail:dr.ainal@gmail.com

Submitted: 23.02 .2013

Accepted: $\quad 7.08 .2013$ 